\title{
Increased richness and diversity of the vaginal microbiota and spontaneous preterm birth
}

\author{
Aline C. Freitas ${ }^{1}$, Alan Bocking ${ }^{2,3}$, Janet E. Hill', Deborah M. Money ${ }^{4,5^{*}}$ and the VOGUE Research Group
}

\begin{abstract}
Background: The bacterial community present in the female lower genital tract plays an important role in maternal and neonatal health. Imbalances in this microbiota have been associated with negative reproductive outcomes, such as spontaneous preterm birth (sPTB), but the mechanisms underlying the association between a disturbed microbiota and SPTB remain poorly understood. An intrauterine infection ascending from the vagina is thought to be an important contributor to the onset of preterm labour. Our objective was to characterize the vaginal microbiota of pregnant women who had SPTB $(n=46)$ and compare to those of pregnant women who delivered at term $(n=170)$. Vaginal swabs were collected from women at 11-16 weeks of gestational age. Microbiota profiles were created by PCR amplification and pyrosequencing of the cpn60 universal target region.

Results: Profiles clustered into seven community state types: I (Lactobacillus crispatus dominated), II (Lactobacillus gasseri dominated), III (Lactobacillus iners dominated), IVA (Gardnerella vaginalis subgroup B or mix of species), IVC (G. vaginalis subgroup A dominated), IVD (G. vaginalis subgroup C dominated) and V (Lactobacillus jensenii dominated). The microbiota of women who experienced preterm birth ( $<37$ weeks gestation) had higher richness and diversity and higher Mollicutes prevalence when compared to those of women who delivered at term. The two groups did not cluster according to CST, likely because CST assignment is driven in most cases by the dominance of one particular species, overwhelming the contributions of more rare taxa. In conclusion, we did not identify a specific microbial community structure that predicts SPTB, but differences in microbiota richness, diversity and Mollicutes prevalence were observed between groups.

Conclusions: Although a causal relationship remains to be determined, our results confirm previous reports of an association between Mollicutes and SPTB and further suggest that a more diverse microbiome may be important in the pathogenesis of some cases.
\end{abstract}

Keywords: Microbiome, Vagina, Lactobacillus, CST, Diversity, Richness, Mollicutes, Preterm birth, Pregnancy, Infection

\section{Background}

Preterm birth is defined as delivery before 37 completed weeks of gestational age [1] and can be further sub-categorized in extremely preterm $\left(\leq 27^{+6}\right.$ weeks $\left.^{+ \text {days }}\right)$, very preterm $\left(28\right.$ to $31^{+6}$ ) and late preterm $\left(32\right.$ to $36^{+6}$ ) [2]. Preterm birth comprises $11 \%$ of all livebirths worldwide, and its complications are estimated to cause $35 \%$ of world's neonatal deaths, which represents 3.1 million

\footnotetext{
* Correspondence: deborah.money@ubc.ca

${ }^{4}$ Department of Obstetrics and Gynaecology, University of British Columbia, Vancouver, BC V6T 1Z4, Canada

${ }^{5}$ Women's Health Research Institute, BC Women's Hospital \& Health Centre, Vancouver, BC V6H 3N1, Canada

Full list of author information is available at the end of the article
}

deaths annually [3]. Children who are born prematurely also have higher rates of cardiovascular disorders, respiratory distress syndrome, neurodevelopmental disabilities and learning difficulties compared with children born at term [4].

Preterm birth is a complex multi-factorial condition with several known risk factors, such as low and high maternal ages [5-7], low BMI [8], black ethnicity [9], tobacco use, heavy alcohol intake, illicit drug use [4], close temporal proximity to a previous delivery [10], and multiple gestation [11]. Although studied extensively, some preterm cases remain unexplained for women with no known risk factors. Intrauterine infection with organisms ascending from the vagina has been hypothesized as an

(c) The Author(s). 2018 Open Access This article is distributed under the terms of the Creative Commons Attribution 4.0 International License (http://creativecommons.org/licenses/by/4.0/), which permits unrestricted use, distribution, and 
important contributor to preterm birth since many organisms isolated from the amniotic fluid/membranes of women who experienced preterm birth are also found in the lower genital tract of pregnant women [12-15]. A large number of studies support this hypothesis based on the strong association between intra-amniotic bacterial infection and preterm birth [12, 14-20].

The microbiological diagnosis of a 'normal' or disturbed vaginal microbiota has historically been based on the Nugent score, the current gold standard diagnostic method that relies on Gram stain of vaginal smears [21]. The 'normal' vaginal microbiota in non-pregnant reproductive aged women is understood to be dominated by Lactobacillus species, while an abnormal microbiota (defined as bacterial vaginosis) is characterized by low abundance of lactobacilli and an overgrowth of anaerobic bacteria, such as Gardnerella vaginalis, Prevotella spp., Bacteroides spp., Mobiluncus spp. and Mycoplasma hominis [22]. In low-risk pregnant women, it has been shown that the vaginal microbiota has reduced richness and diversity and increased abundance of lactobacilli compared to those of non-pregnant women [23-27]. An abnormal microbiota has been previously associated with preterm birth [28], but only a few in depth culture-independent studies of the vaginal microbiota of women who had preterm birth have been published, with inconsistent conclusions [29-32].

The objective of this study was to assess whether there are differences in the vaginal microbiota composition, early in gestation, of women who had spontaneous preterm birth (sPTB) and term delivery that could be further investigated as diagnostic indicators of preterm birth risk. Microbiome profiling was based on sequencing of the cpn60 universal target, which provides higher resolution than 16S rRNA variable regions [33] and allows the resolution of Gardnerella vaginalis subgroups, a hallmark bacteria in the disturbed microbiota [34].

\section{Methods}

\section{Study population and sampling}

This retrospective cohort study analysed the vaginal microbiota of women who experienced spontaneous preterm birth (sPTB) and compared the resulting microbial profiles to those of pregnant women who delivered at term. The bacterial profiles of pregnant Canadian women at low risk of SPTB who had term deliveries $(n=170)$ were previously generated by our research group [24]. The vaginal microbial profiles of Canadian women who had preterm birth originated from samples of this previous study $(n=7)$ [24] and from the Ontario Birth Study $(n=39)$, resulting in 46 samples. The Ontario Birth Study (ontariobirthstudy.com) is an open longitudinal pregnancy cohort at Mount Sinai Hospital, Toronto, Canada. It is a platform for studies of both pregnancy complications as well as Developmental Origins of Health and Disease related research. The PTB rates for the low-risk cohort and OBS cohorts were 4 and $6.2 \%$, respectively. All biospecimens, including maternal vaginal swabs and maternal and infant blood, are collected concurrently with routine clinical specimens to reduce the burden on study participants. Detailed demographic and lifestyle characteristics are obtained from women during pregnancy and postpartum, and clinical information is extracted from the health records. For the purposes of this report, self-administered vaginal swabs were taken at 16 weeks gestation and placed in dry tubes prior to being placed in $-80^{\circ} \mathrm{C}$ for storage in the Lunenfeld Tanenbaum Research Institute Biospecimen Storage and Processing Laboratory. Specimens from all cohorts were processed similarly in terms of sample collection, storage, DNA extraction, library preparation and sequencing.

Clinical and behavioural questionnaire data (pregnancy history, family and personal medical history, psychosocial health, demographic factors and other lifestyle and environmental exposures) were transferred to the Research Electronic Data Capture (REDCap) database protected by a secure server [35]. For the PTB group, eligible participants for this study were women who had undergone preterm delivery at greater than 20 weeks but less than 37 weeks gestational age, where onset of labour occurred spontaneously or in association with cervical incompetence or preterm premature rupture of membranes (PPROM). Vaginal swabs collected from pregnant women (both PTB and term groups) at 11-16 weeks of gestational age were used for bacterial genomic analysis.

Total nucleic acid was extracted from swabs using the MagMAX $^{\text {su }}$ Total Nucleic Acid Isolation Kit (Life Technologies, Burlington, ON, Canada) as per manufacturer's instructions. Kit reagents are aliquoted to eliminate repeated accessing of open reagents, and samples are processed in small batches using filter tips to prevent cross-contamination. Pipettes and other lab surfaces are regularly treated with DNA surface decontaminant (DNA Away, Thermo Fisher Scientific, Waltham, MA). Samples from both cohorts were processed in exactly the same way in terms of swab type, storage temperature (no stabilizer was used), DNA extraction, library preparation and sequencing.

\section{Total bacterial DNA (qPCR) and detection of Mollicutes (PCR) Quantitative PCR ( $q P C R$ )}

Total bacterial DNA quantity in each sample was estimated using a SYBR Green assay based on amplification of the V3 region of the 16S rRNA gene. Primer sequences were as follows: SRV3-1 (5'-CGGYCCAG ACTCCTAC-3'), SRV3-2 (5' -TTACCGCGGCTGCT GGCAC-3') [36]. Reactions were run on a MyiQ thermocycler using the following cycling parameters: $95{ }^{\circ} \mathrm{C}$ 
for $3 \mathrm{~min}$, followed by 30 cycles of $95{ }^{\circ} \mathrm{C}$ for $15 \mathrm{~s}, 62{ }^{\circ} \mathrm{C}$ for $15 \mathrm{~s}$ and $72{ }^{\circ} \mathrm{C}$ for $15 \mathrm{~s}$, with a final extension at $72{ }^{\circ} \mathrm{C}$ for $5 \mathrm{~min}$ [37].

\section{Conventional PCR}

Some Mollicutes (Mycoplasma and Ureaplasma) species lack a cpn60 gene [38]. Thus, we performed a familyspecific semi-nested PCR targeting the 16S rRNA gene to detect Mollicutes [39], and a PCR targeting the multiple-banded antigen gene to detect Ureaplasma spp. PCR products from $U$. parvum and $U$. urealyticum can be differentiated by size [40].

\section{cpn60 universal target (UT) PCR and pyrosequencing}

Universal primer PCR targeting the $549-567$ bp cpn60 UT region was performed using a mixture of cpn60 primers consisting of a 1:3 M ratio of primers $\mathrm{H} 279$ / $\mathrm{H} 280: \mathrm{H} 1612 / \mathrm{H} 1613$, as described previously [41-43]. To allow multiplexing of samples in a single sequencing run, primers were modified at the $5^{\prime}$ end with one of 24 unique decamer multiplexing identification (MID) sequences, as per the manufacturer's recommendations (Roche, Brandford, CT, USA). Amplicons were pooled in equimolar amounts for sequencing on the Roche GS Junior sequencing platform. The sequencing libraries were prepared using the GS DNA library preparation kit, and emulsion PCR (emPCR) was performed with a GS emPCR kit (Roche Diagnostics, Laval, Canada).

Samples were handled in small batches to avoid cross-contamination, and experimental controls were included at several steps in the study. Regular monitoring of DNA extraction controls in our lab by universal PCR confirms that these procedures are sufficient to eliminate detectable template contamination of study samples. A no template control was also included in each set of PCR reaction as negative controls. Experimental controls were not sequenced as they did not yield any amplification.

\section{Analysis of operational taxonomic units (OTU)}

Raw sequence data was processed by using the default on-rig procedures from 454/Roche. Filter-passing reads were used in the subsequent analyses for each of the pyrosequencing libraries. MID-partitioned sequences were mapped using Bowtie 2 (http://bowtie-bio.sourceforge. net/bowtie2/) on to a manually curated reference set of 1561 OTU sequences representing the human vaginal microbiota. Bowtie 2 was run using the default end-to-end alignment mode.

The OTU reference set was generated originally by de novo assembly of cpn60 sequence reads from 546 vaginal microbiomes using the microbial Profiling Using Metagenomic Assembly pipeline (mPUMA, http://mpuma. sourceforge.net) [44] with Trinity as the assembly tool [45] (Additional file 1). OTU were labeled according to their nearest reference sequence determined by watered-Blast comparison [46] to the cpn60 reference database, cpnDB_nr (downloaded from http:// www.cpndb.ca [38]). This reference assembly approach allows us to compare the microbial profiles from various cohorts under investigation, including the 46 pregnant women who had SPTB described in this study.

The result of mapping is an OTU frequency table (Additional file 2) that was used for microbiome data analysis. Some analyses were also performed at species level, i.e. combined OTU that have the same nearest neighbour.

\section{Statistical analysis}

Comparisons of socio-demographic characteristics of cohorts and participants were based on analysis of variance (ANOVA), $t$ test and chi-square, performed in IBM SPSS (Statistical Package for the Social Sciences, version 21) at $5 \%$ level of significance. For analysis of associations between socio-demographic characteristics and microbiota profiles (CST), a false discovery rate (FDR) correction for multiple comparisons was applied [47].

Alpha (Shannon diversity and Chao1 estimated species richness) and beta diversity (jackknifed Bray-Curtis dissimilarity matrices) were calculated as the mean of 100 subsamplings of 1000 reads (or all reads available when less than 1000) in QIIME (Quantitative Insights Into Microbial Ecology) [48]. Plots of alpha diversity measures against bootstrap sample number were generated in $R$ and visually inspected to ensure that an adequate sampling depth for each sample was achieved.

For community state type (CST) analysis, a JensenShannon distance matrix was calculated using the 'vegdist' function in the vegan package [49] with a custom distance function that calculates the square root of the Jensen-Shannon divergence [50]. This distance matrix was used for hierarchical clustering using the 'hclust' function in $\mathrm{R}$, with Ward linkage.

The function aldex.clr from the ALDEx2 package in $\mathrm{R}$ was used to compare the differential relative abundance of individual taxa in term and preterm groups [51]. Significant differences were determined based on the false discovery rate (FDR), which is the result of a BenjaminiHochberg corrected $p$ value from a Welch's $t$ test calculated within ALDEx2.

\section{Results}

Description of the study population and pregnancy outcomes Socio-demographic characteristics of women who had spontaneous preterm birth $(n=46)$ and women who had term deliveries $(n=170)$ are summarized in Table 1. There were no significant differences in maternal age, BMI, ethnicity, smoking status, consumption of alcohol or use of probiotics between term and preterm groups (all $p>0.05$ ). Average maternal age was 33 for 
Table 1 Socio-demographic and microbiological characteristics of subjects

\begin{tabular}{|c|c|c|c|}
\hline Characteristics & Term pregnancies $(n=170)$ & $\begin{array}{l}\text { Preterm pregnancies } \\
(n=46)\end{array}$ & $p$ value \\
\hline $\mathrm{Age}_{(\text {mean } \pm S D}$, range $)^{1}$ & $33.6 \pm 4.2(21-45)$ & $33.65 \pm 4.1(25-45)$ & 0.948 \\
\hline $21-25$ & $5(2.9 \%)$ & $1(2.1 \%)$ & \\
\hline $26-35$ & $114(67.1 \%)$ & $32(69.5 \%)$ & \\
\hline $36-45$ & $51(30.0 \%)$ & $13(28.2 \%)$ & \\
\hline $\mathrm{BMI}(\text { mean } \pm \mathrm{SD} \text {, range })^{1}$ & $22.9 \pm 3.8(17-40)$ & $24.2 \pm 5.6(19-43)$ & 0.125 \\
\hline Underweight $(<18.50)$ & $7(4.1 \%)$ & $0(0 \%)$ & \\
\hline Normal weight (18.51-24.9) & $131(77.0 \%)$ & $33(73.3 \%)$ & \\
\hline Overweight (25.0-29.9) & $25(14.7 \%)$ & $8(17.7 \%)$ & \\
\hline Obese (> 30) & $7(4.1 \%)$ & $4(9.0 \%)$ & \\
\hline$M D^{3}$ & $0(0 \%)$ & $1(2.2 \%)$ & \\
\hline Ethnicity $^{2}$ & & & 0.261 \\
\hline White & $108(63.5 \%)$ & $22(47.8 \%)$ & \\
\hline East Asian & $26(15.3 \%)$ & $6(13.0 \%)$ & \\
\hline South/Southeast Asian & $15(8.8 \%)$ & $4(8.7 \%)$ & \\
\hline Latin America/Hispanic & $8(4.7 \%)$ & $3(6.5 \%)$ & \\
\hline Black & $3(1.8 \%)$ & $2(4.4 \%)$ & \\
\hline Other/mixed ethnicity & $10(5.9 \%)$ & $6(13.0 \%)$ & \\
\hline MD & $0(0 \%)$ & $3(6.5 \%)$ & \\
\hline Community state type $(\mathrm{CST})^{2}$ & & & 0.361 \\
\hline 1 & $56(32.9 \%)$ & 17 (37\%) & \\
\hline$\|$ & $9(5.3 \%)$ & $5(10.9 \%)$ & \\
\hline III & $28(16.5 \%)$ & $8(17.4 \%)$ & \\
\hline IVA & $31(18.2 \%)$ & $6(13 \%)$ & \\
\hline IVC & $19(11.2 \%)$ & $2(4.3 \%)$ & \\
\hline IVD & $11(6.5 \%)$ & $1(2.2 \%)$ & \\
\hline V & $16(9.4 \%)$ & $7(15.2 \%)$ & \\
\hline Estimated bacterial load (log copies of $16 \mathrm{~S} r R N A$ gene)/swab (mean \pm SD, range) ${ }^{1}$ & $7.78 \pm 0.93(4.89-10.67)$ & $8.07 \pm 0.71(6.32-10.33)$ & 0.049 \\
\hline Presence of Mollicutes ${ }^{2}$ & $68(40 \%)$ & $28(60.8 \%)$ & 0.012 \\
\hline Presence of Ureaplasma ${ }^{2}$ & $40(23.4 \%)$ & $14(30.4 \%)$ & 0.337 \\
\hline U. parvum & $37(21.7 \%)$ & $14(30.4 \%)$ & \\
\hline U. urealyticum & $3(1.7 \%)$ & $0(0 \%)$ & \\
\hline Shannon diversity (mean $\pm \mathrm{SD}$, range) ${ }^{1}$ & $1.28 \pm 0.86(0.13-4.52)$ & $1.81 \pm 1.13(0.34-5.16)$ & 0.004 \\
\hline 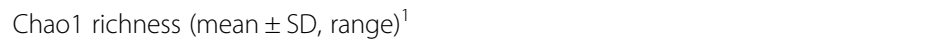 & $36.22 \pm 14.80(14.39-115.74)$ & $46.38 \pm 24.19(20.20-126.01)$ & 0.009 \\
\hline
\end{tabular}

${ }^{1} t$ test; ${ }^{2}$ chi-square; ${ }^{3} \mathrm{MD}=$ missing data

participants in both cohorts. Average body mass index (BMI) was 22.9 and 24.2 for women in the term and preterm groups, respectively. Most women in both cohorts identified themselves as white ethnicity, followed by East Asian and South/Southeast Asian (Table 1). Consumption of tobacco (term 2.3\%; preterm 0\%), alcohol (term $5.9 \%$; preterm $4.3 \%$ ) or probiotic supplements (term 4.1\%; preterm $6.5 \%$ ) was low among women in both groups (chi-square, all $p>0.05$ ).

Most women in the preterm group had a Bachelor/ graduate degree (29/46) and an average house income higher than CAD 100,000 per year (25/46). A minority of women who had preterm birth (5/46) reported consumption of substances without prescription prior pregnancy, of which 3/46 women consumed marijuana/ hashish, 1/46 woman consumed tranquilizers/nerve pills and 1/46 woman consumed cocaine/crack. Approximately $74 \%$ of the participants in the preterm group reported a pre-existing condition. A total of 12/46 women had some condition related to mental health, such depression or anxiety. Seventeen percent $(8 / 46)$ had a neurological condition, including migraine headaches, 
and $24 \%(11 / 46)$ had a genitourinary condition (corpus luteal cyst, bicornuate uterus, cervical polyp, cervical dysplasia (2), uterine polyp, ovarian cyst, polycystic ovarian syndrome, urinary tract infections with and without kidney stones (3).

Characteristics regarding pregnancy and neonatal outcomes are described in Table 2. Pregnancy outcome information was not available for one woman in the preterm group as she was lost to follow-up. There were no significant differences in gestational age at enrolment, mode of conception or fetal sex between groups (all $p>0.05$ ). Average gestational age at delivery was $39^{+3}$ weeks for the women who delivered at term and $34^{+2}$ weeks for women who had preterm birth, most of which were considered late preterm, i.e. delivery between 32 and $36^{+6}$ weeks of gestational age. Women in the preterm group were more likely to have experienced preterm birth or miscarriage in their previous pregnancy (chi-square, $p<0.001$ ). They also had higher percentage of caesarean sections than women who delivered at term. Number of previous gestations also differed between groups; women who had preterm birth were more likely to be primigravida (22/46) in comparison with women who had term deliveries (45/170). There was a significant difference between term and preterm groups regarding birth weight and number of infants admitted to level 3 neonatal intensive care unit (NICU) (Table 2). Apgar score at 1 (term $8.75 \pm 0.6$; preterm $8.38 \pm 1.1$ ) and 5 min (term $8.97 \pm 0.17$; preterm $8.76 \pm 0.7$ ) between groups also differed $(t$ test, all $p<0.001)$. One preterm infant (1/46) died shortly after birth (20 weeks of gestational age).

Among women who delivered preterm, 63\% (29/46) had premature rupture of membranes (PPROM), 10.8\% $(5 / 46)$ had gestational diabetes and $4.3 \%(2 / 46)$ had anemia unresponsive to therapy. Twenty-four percent of women (11/46) presented one of the following conditions: maternal elevated liver enzymes, short cervix and incompetent cervix; fetal ascites, fetal distress and large foetus for gestational age; and placental findings of marginal cord insertion, two-vessel umbilical cord, placenta previa and low-lying placenta.

\section{Sequencing results and OTU analysis}

Raw sequence data files for the samples described in this study were deposited to the NCBI Sequence Read Archive (Accession SRP073152, BioProject PRJNA317763;

Table 2 Gestation characteristics, pregnancy and neonatal outcomes

\begin{tabular}{|c|c|c|c|}
\hline Characteristics & Term pregnancies $(n=170)$ & Preterm pregnancies $(n=46)$ & $p$ value \\
\hline \multicolumn{4}{|l|}{ Gestational age in weeks ${ }^{\text {day }}$} \\
\hline At enrolment (mean $\pm \mathrm{SD}$, range) ${ }^{1}$ & $13^{+2} \pm 1^{+1}\left(11^{+1}-16^{+6}\right)$ & $13^{+3} \pm 1^{+0}\left(11^{+6}-16^{+0}\right)$ & 0.641 \\
\hline At delivery (mean $\pm \mathrm{SD}$, range $)^{1}$ & $39^{+3} \pm 0^{+6}\left(39^{+3}-41^{+2}\right)$ & $34^{+2} \pm 2^{+6}\left(20^{+0}-36^{+6}\right)$ & $<0.0001$ \\
\hline Late preterm ( 32 to $36^{+6}$ ) & NA & $39(84.8 \%)$ & \\
\hline Very preterm (28 to $31^{+6}$ ) & NA & $5(10.8 \%)$ & \\
\hline Extremely early $\left(\leq 27^{+6}\right)$ & NA & $1(2.1 \%)$ & \\
\hline Previous pregnancy history (excludes women in first pregnancy) ${ }^{2}$ & $(n=125)$ & $(n=24)$ & $<0.0001$ \\
\hline Livebirth, term & $89(71.2 \%)$ & $9(37.5 \%)$ & \\
\hline Livebirth, preterm & $0(0 \%)$ & $3(12.5 \%)$ & $<0.0001$ \\
\hline Spontaneous abortion & $20(16 \%)$ & $8(33.3 \%)$ & 0.046 \\
\hline Pregnancy termination & $16(12.8 \%)$ & $3(12.5 \%)$ & 0.968 \\
\hline Ectopic pregnancy & $0(0 \%)$ & $1(4.1 \%)$ & \\
\hline Mode of delivery ${ }^{2}$ & & & 0.042 \\
\hline Vaginal delivery & $128(75.3 \%)$ & $27(58.7 \%)$ & \\
\hline C-section & $42(24.7 \%)$ & $18(39.1 \%)$ & \\
\hline Parity $^{2}$ & & & 0.005 \\
\hline 0 & $55(32.3 \%)$ & $28(60.8 \%)$ & \\
\hline 1 & $94(55.3 \%)$ & $12(26 \%)$ & \\
\hline $2-4$ & $21(12.3 \%)$ & $6(13 \%)$ & \\
\hline Assisted conception ${ }^{2}$ & $17(10 \%)$ & $6(13 \%)$ & 0.591 \\
\hline Fetal sex ( $\%$ male $/ \%$ female) ${ }^{2}$ & $(48.8 \%) /(51.1 \%)$ & $(41.3 \%) /(56.5 \%)$ & 0.430 \\
\hline Birth weight $(\mathrm{g})(\text { mean } \pm \mathrm{SD} \text {, range })^{1}$ & $3398 \pm 459(1970-5200)$ & $2550 \pm 559(1300-3595)$ & $<0.0001$ \\
\hline Infant in NICU $(n, \%)^{2}$ & $1(0.6 \%)$ & $24(52.2 \%)$ & $<0.0001$ \\
\hline
\end{tabular}

${ }^{1} t$ test; ${ }^{2}$ chi-square 
BioProject PRJNA403856). Total dataset contained $1,635,072$ cpn60 reads; median and average read count per sample were 4936 and 7569 (range 402-37,378), respectively. Average read length was $424 \mathrm{bp}$. Results of Bowtie2 mapping showed that these reads corresponded to 728 OTUs from the reference assembly (Additional file 1).

\section{Microbiota profiles}

Microbiota profiles were created by PCR amplification and pyrosequencing of the cpn60 universal target region. Hierarchical clustering of vaginal microbiota profiles resulted in seven community state types (CST): I (Lactobacillus crispatus dominated), II (Lactobacillus gasseri dominated), III (Lactobacillus iners dominated), IVA (Gardnerella vaginalis subgroup B or mix of different species), IVC (G. vaginalis subgroup A dominated), IVD (G. vaginalis subgroup $\mathrm{C}$ dominated) and $\mathrm{V}$ (Lactobacillus jensenii dominated) (Fig. 1). Each CST is defined by the dominance of one species of Lactobacillus (I, II, III, V), Gardnerella vaginalis (IVC, IVD) or a mixture of bacteria species (IVA), as previously described [52, 53].

Overall microbiota profiles did not cluster together based on gestational age at delivery (Figs. 1 and 2). Most microbial profiles from the preterm group (80.5\%) were assigned to Latobacillus-dominated CST: CST I (37\% of profiles), CST III (17.4\%), CST V (15.2\%) and CST II (10.9\%). The remaining profiles (19.5\%) were assigned to CST IVA, IVC or IVD (Table 1). The CST IVA was the most heterogeneous group, represented by the dominance of Lactobacillus delbrueckii, Bifidobacterium dentium, Bifidobacterium infantis, Atopobium vaginae, Bifidobacterium breve or a mixture of different bacteria species. The CST IVC was dominated by G. vaginalis subgroup A and Megasphaera spp., and CST IVD was dominated by G. vaginalis subgroup C (Fig. 1).

\section{Ecological analysis and total bacterial load}

Assessment of alpha diversity revealed that microbiomes of women who delivered preterm were richer (Chao1 richness $46.3 \pm 24.1$ ) and more diverse (Shannon diversity index $1.8 \pm 1.1$ ) when compared to those of women in the term group $(36.2 \pm 14.8 ; 1.2 \pm 0.8)(t$ test, $p<0.01)$ (Table 1). Total bacterial load was estimated based on qPCR targeting the 16S rRNA gene, and it was expressed as $\log 16 \mathrm{~S}$ rRNA gene copy number per swab. Higher bacterial loads were detected in samples from the preterm group $(7.7 \pm 0.9)$ compared to term group $(8.0 \pm 0.7)(t$ test, $p=0.049)$ (Table 1$)$.

\section{Bacteria species relative abundance and prevalence}

To investigate whether there was an association between individual taxa and SPTB, the abundance and prevalence of each species was evaluated. The ALDEx2 analysis assessed the relative abundance of each taxa (at the OTU and species level) in term and preterm groups. Eight OTU/species were more abundant in the term group in comparison with preterm, all of which were considered rare members of the bacterial community (Fig. 3). L. acidophilus represented $1 \%$ of the total reads in the dataset and had a low relative abundance average of $1.98 \%$ (range $0-69 \%$ ) and $0.18 \%$ (range $0-0.87 \%$ ) in samples from term and preterm groups respectively. All the other seven bacteria together represented only $0.4 \%$ of the total reads in the dataset.

Bacteria prevalence (presence/absence) was also assessed (only species with at least 10 total reads were included). A total of 60 taxa had significant differences in prevalence between term and preterm groups; 11 species had greater prevalence in the term cohort and 49 species were more prevalent in the preterm cohort (Table 3). Bifidobacterium infantis, for example, was two times more prevalent in the term group in comparison with preterm, and Prevotella timonensis was 1.58 times more prevalent in the preterm group (Table 3). Several Prevotella spp. were associated with both term and preterm. Prevotella amnii and $P$. tannerae had greater prevalence in the term cohort, whereas $P$. timonensis, $P$. bivia, $P$. corporis and $P$. bucalis were more prevalent in the preterm group (Table 3). It is important to note that read depth distribution did not differ between term and preterm cohorts $(t$ test, $p>0.05)$; therefore, the differences observed here in bacteria prevalence were unlikely to be driven by cohort sequencing bias.

Mollicutes (Mycoplasma and/or Ureaplasma) were detected by family-specific conventional PCR in 28/46 $(60 \%)$ of pregnant women who delivered preterm (Table 1). Ureaplasma species were detected by genus-specific PCR in samples of 14/46 (30\%) women who had PTB, with all women testing positive for $U$. parvum and none for $U$. urealyticum. Women who delivered at term were less likely to be PCR positive for Mollicutes compared to women who had PTB (Table 1). No significant differences were observed in Ureaplasma prevalence between the two groups (Table 1). An association between Mollicutes/Ureaplasma detection and the composition of the vaginal microbiota, represented as CST, was also investigated. Detection of Mollicutes and Ureaplasma was not associated with any CST in particular when investigated in the term cohort, preterm cohort or both groups together (chi-square, $p>0.05$ ).

\section{Relationships between microbiological and socio-demographic characteristics within the preterm group}

The association between CST (I, II, III, IVC, IVD, V) from profiles of women who delivered preterm and several microbiologic-socio-demographic characteristics was investigated. Only two associations were significant: 


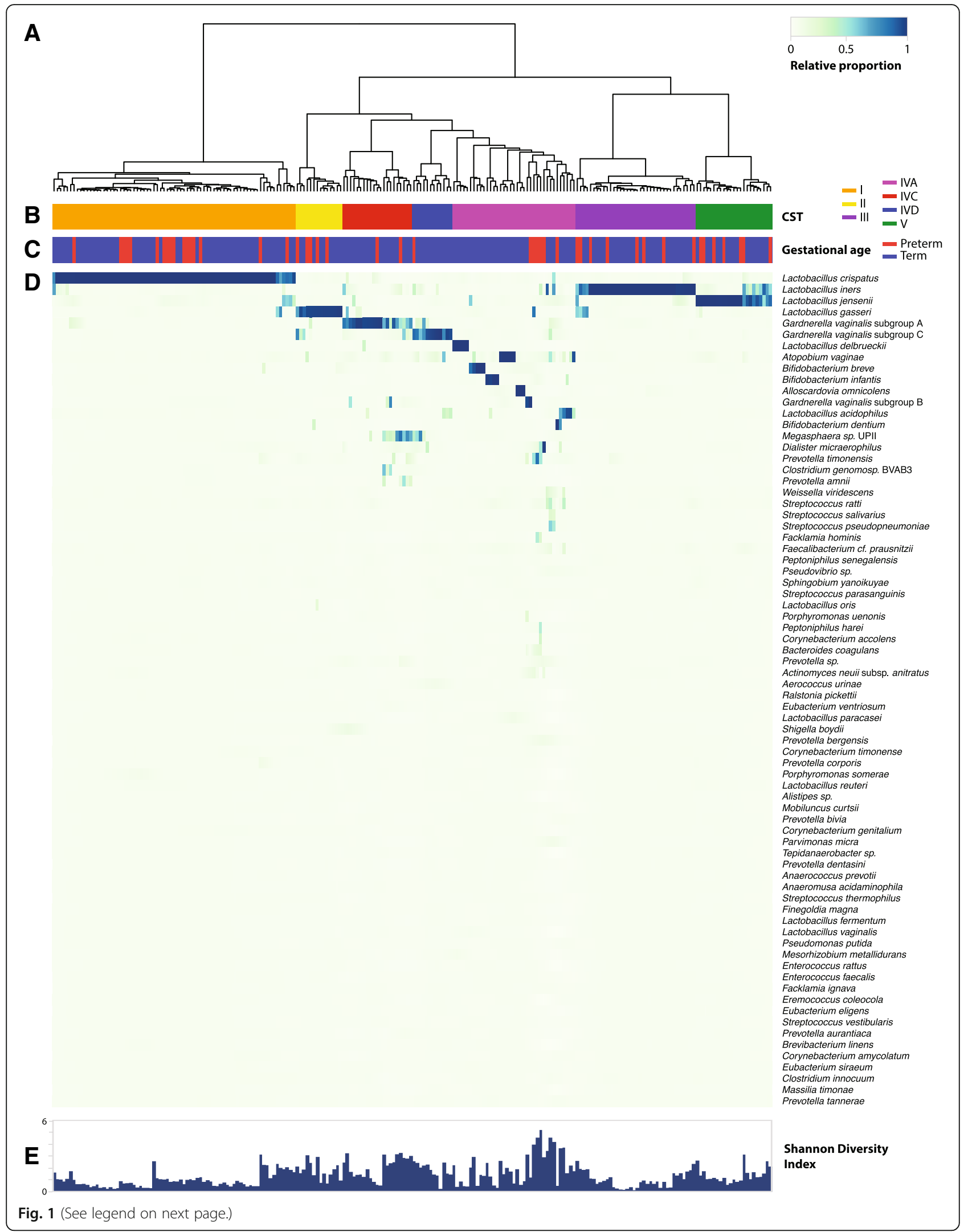


(See figure on previous page.)

Fig. 1 Vaginal microbiota profiles of women who had SPTB and term deliveries. a Hierarchical clustering of Jensen-Shannon distance matrices with Ward linkage on the relative proportions of reads for each OTU within individual vaginal samples. b Community state type (CST). c Gestational age at delivery. $\mathbf{d}$ Heatmap of relative abundances of bacterial species within each vaginal microbiota. Each column represents a woman's vaginal microbiota profile, and each row represents a bacteria species. Only species that are at least $1 \%$ abundant in at least one sample are shown. e Shannon diversity indices calculated for each sample

CST and microbiota richness, and CST and microbiota diversity (ANOVA, $p<0.001$ ). There was no significant association between CST and the remaining following metadata: microbiota richness and diversity (continuous variable), presence of Mollicutes and Ureaplasma (yes/ no), $\log 16 \mathrm{~S}$ rRNA gene copies (continuous variable), maternal age (continuous variable; 18-25, 26-35, 36-45), BMI category (underweight, normal, overweight, obese; <25, $\geq 25$ ), ethnicity (White, East Asian, South Asian, Black, Hispanic, Other), natural conception (yes/no), parity $(0,>1)$, gestational age (continuous variable), mode of delivery (vaginal, C-section), pre-existing condition (yes/no), folic acid intake before or during pregnancy (yes/no), drinking alcohol (yes/no), neonate in high level care (yes/no), birth weight (continuous variable) and Apgar score at 1 and 5 min (1-9).

\section{Discussion}

In this study, we determined the composition of the vaginal microbiota of women who had spontaneous preterm birth and compared these profiles to those of women who delivered at term, previously reported by our research group [24]. The availability of foundational data on women who delivered at term and the infeasibility of collecting large numbers of samples at 11-16 weeks gestation from women who would go on to deliver pre-term, our study design included comparison of samples collected in a previously published study [24] and from the OBS. To minimize any batch effects, we were rigorous in implementation of consistent sample processing and did extensive analysis of the clinical and demographic characteristics to ensure they were well matched (Table 1). The cohorts were comparable in terms of maternal age, BMI, ethnicity, consumption of tobacco, alcohol and probiotics, which is of interest given that several of these characteristics have been previously associated with preterm delivery. In particular, previous described factors included low and high maternal ages [5-7], low BMI [8], black ethnicity [9], high levels of tobacco, alcohol and illicit drugs consumption [4], close temporal proximity to a previous delivery [10] and multiple gestation [11]. This cohort is unique in that it did offer the opportunity to have gestational age at delivery as the main characteristic distinguishing these two groups recognizing that the majority of preterm births occurred beyond 32 weeks gestation.

A difference in number of previous gestations was observed between groups, with women who experienced preterm birth more likely to be primigravida in comparison with women who had term deliveries. It has been recently demonstrated that women with a prior conception, regardless of whether or not this proceeded to a birth, have a decrease in the relative abundance of L. crispatus and a concomitant increase in the

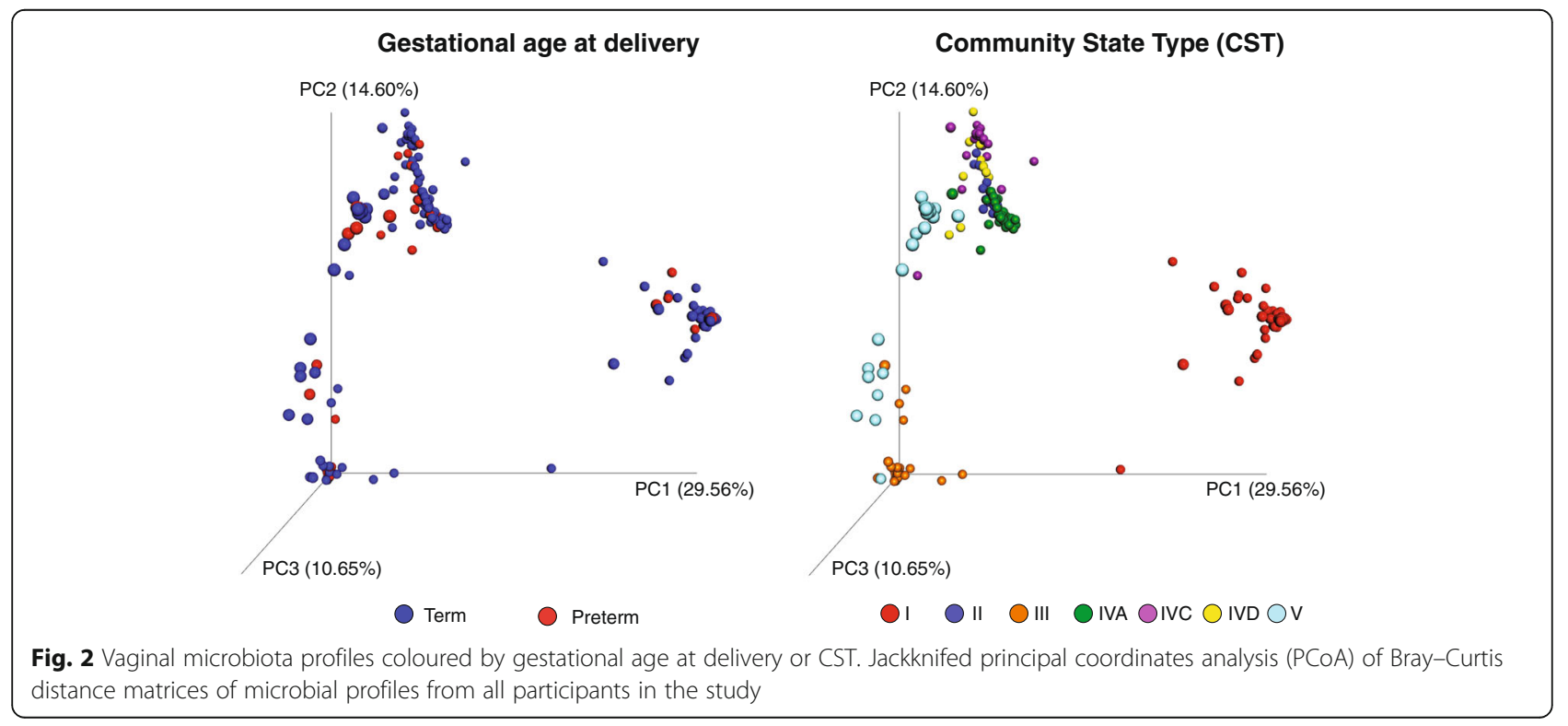




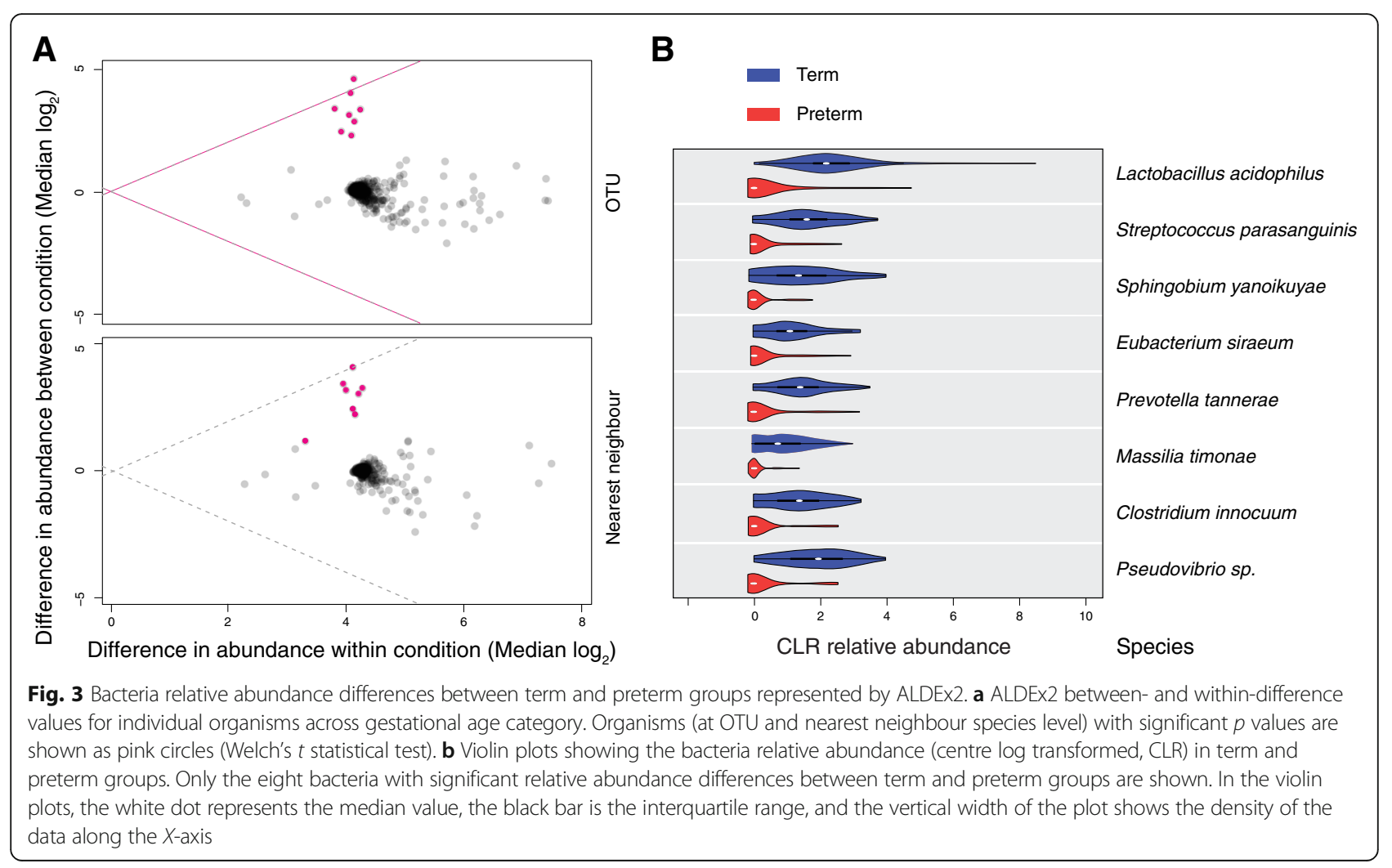

abundance of other Lactobacillus species as well as Gardnerella [54].

Other known risk factors for sPTB include maternal medical disorders like hypertension, asthma, diabetes and thyroid disease [4]. Although some women in both cohorts reported these conditions, there were not enough participants to stratify the data based on the individual disorder and therefore was not possible to investigate the interaction between those medical conditions and gestation outcome. We were, however, able to confirm previous reports of history of prematurity as a risk factor for preterm birth [55].

Since many organisms isolated from the amniotic cavity of women who experienced preterm birth are also found in the genital tract [12-15], an intrauterine infection ascending from the vagina is one of the currently hypothesized triggers of PTB [56]. In this study, however, we did not identify a signature microbiota composition (CST) associated with preterm birth. This observation is consistent with the results presented by others $[29,30]$. CST assignments are largely driven by the dominance of a single species, which may mask differences in rare taxa that would differentiate term and preterm groups, and indeed, further analysis revealed that the vaginal microbiota of women who experienced preterm birth was richer and more diverse than those of women who delivered at term. Also, most women $(84.8 \%)$ in our study were considered late preterm and although we cannot address this question, it is possible that SPTB driven by an ascending infection would be more evident in a high-risk cohort or extreme preterm cases. A recent study of a high-risk pregnant cohort has reported that $L$. iners was strongly associated with short cervix and preterm birth, as L. crispatus was associated with term deliveries [57]. Those differences in study outcomes indicate that the pathogenesis of sPTB in lowand high-risk groups might be different. Identifying differences in the causes of early and late sPTB and the role of the vaginal microbiota in those processes will require further study.

One controversy that challenges the current hypothesis of preterm caused by an ascending infection is that antibiotic administration to pregnant women with a disturbed vaginal microbiota does not improve outcome in most cases, as demonstrated by study trials $[58,59]$ and systematic reviews [60-62]. One explanation for the inefficacy of antibiotic treatment in the prevention of preterm birth relies is the high rates of antibiotic resistance among bacterial-vaginosis-associated bacteria [63, 64]. In this case, antibiotics not only do not kill the targeted bacteria, but might also reduce the vaginal Lactobacillus population leading to an even more disturbed microbiota, as recently demonstrated [65].

In addition to differences in richness and diversity, differences in the microbiota between the two cohorts regarding bacterial abundance and prevalence were also 
Table 3 Bacteria prevalence in the vaginal microbiomes of women who delivered preterm and at term

\begin{tabular}{|c|c|c|c|c|c|c|c|}
\hline \multirow[t]{2}{*}{ Species } & \multirow{2}{*}{$\begin{array}{l}\text { Total } \\
\text { reads }\end{array}$} & \multicolumn{2}{|c|}{ Preterm $(n=46)$} & \multicolumn{2}{|c|}{ Term $(n=170)$} & \multirow{2}{*}{$\begin{array}{l}\text { Prevalence } \\
\text { ratio }\end{array}$} & \multirow[t]{2}{*}{$\mathrm{FDR}^{*}$} \\
\hline & & Reads & Prevalence (\%) & Reads & Prevalence (\%) & & \\
\hline A & & & & & & term/preterm & \\
\hline Bifidobacterium infantis & 56,246 & 409 & 19.57 & 55,837 & 40.00 & 2.04 & 0.033 \\
\hline Lactobacillus delbrueckii subsp. lactis & 48,063 & 9 & 4.35 & 48,054 & 28.82 & 6.63 & 0.005 \\
\hline Lactobacillus acidophilus & 17,440 & 569 & 89.13 & 16,871 & 97.65 & 1.10 & 0.033 \\
\hline Prevotella amnii & 13,339 & 68 & 4.35 & 13,271 & 21.76 & 5.01 & 0.023 \\
\hline Pseudovibrio sp. & 1634 & 52 & 15.22 & 1582 & 91.76 & 6.03 & 0.000 \\
\hline Streptococcus parasanguinis & 1199 & 63 & 19.57 & 1136 & 88.82 & 4.54 & 0.000 \\
\hline Sphingobium yanoikuyae & 1174 & 16 & 13.04 & 1158 & 80.00 & 6.13 & 0.000 \\
\hline Prevotella tannerae & 930 & 58 & 15.22 & 872 & 88.24 & 5.80 & 0.000 \\
\hline Clostridium innocuum & 814 & 42 & 13.04 & 772 & 81.18 & 6.22 & 0.000 \\
\hline Eubacterium siraeum & 641 & 43 & 17.39 & 598 & 78.24 & 4.50 & 0.000 \\
\hline Massilia timonae & 426 & 6 & 8.70 & 420 & 70.00 & 8.05 & 0.000 \\
\hline B & & & & & & preterm/term & \\
\hline Prevotella timonensis & 11,450 & 4211 & 71.74 & 7239 & 45.29 & 1.58 & 0.005 \\
\hline Dialister micraerophilus & 7381 & 2850 & 67.39 & 4531 & 44.12 & 1.53 & 0.021 \\
\hline Prevotella sp. & 2216 & 626 & 47.83 & 1590 & 14.71 & 3.25 & 0.000 \\
\hline Bacteroides coagulans & 1283 & 1212 & 41.30 & 71 & 7.06 & 5.85 & 0.000 \\
\hline Corynebacterium accolens & 1083 & 999 & 52.17 & 84 & 13.53 & 3.86 & 0.000 \\
\hline Porphyromonas uenonis & 1040 & 795 & 28.26 & 245 & 12.94 & 2.18 & 0.038 \\
\hline Actinomyces neuii subsp. anitratus & 877 & 738 & 43.48 & 139 & 10.00 & 4.35 & 0.000 \\
\hline Peptoniphilus harei & 875 & 811 & 45.65 & 64 & 7.65 & 5.97 & 0.000 \\
\hline Lactobacillus fermentum & 729 & 664 & 17.39 & 65 & 5.29 & 3.29 & 0.026 \\
\hline Facklamia hominis & 711 & 709 & 15.22 & 2 & 1.18 & 12.93 & 0.000 \\
\hline Prevotella bivia & 638 & 228 & 26.09 & 410 & 8.24 & 3.17 & 0.005 \\
\hline Prevotella corporis & 535 & 463 & 23.91 & 72 & 5.88 & 4.07 & 0.000 \\
\hline Corynebacterium timonense & 503 & 355 & 34.78 & 148 & 10.00 & 3.48 & 0.000 \\
\hline Corynebacterium genitalium & 372 & 323 & 34.78 & 49 & 7.06 & 4.93 & 0.000 \\
\hline Tepidanaerobacter sp. & 329 & 303 & 23.91 & 26 & 4.12 & 5.81 & 0.000 \\
\hline Corynebacterium amycolatum & 264 & 228 & 32.61 & 36 & 4.71 & 6.93 & 0.000 \\
\hline Parvimonas micra & 193 & 183 & 10.87 & 10 & 1.18 & 9.24 & 0.005 \\
\hline Mobiluncus curtsii subsp. curtsii & 183 & 171 & 21.74 & 12 & 2.35 & 9.24 & 0.000 \\
\hline Finegoldia magna & 155 & 149 & 13.04 & 6 & 3.53 & 3.70 & 0.038 \\
\hline Coprococcus eutactus & 154 & 68 & 47.83 & 86 & 27.06 & 1.77 & 0.026 \\
\hline Brevibacterium linens & 147 & 142 & 10.87 & 5 & 0.59 & 18.48 & 0.000 \\
\hline Rothia dentocariosa & 144 & 120 & 30.43 & 24 & 5.29 & 5.75 & 0.000 \\
\hline Streptococcus thermophilus & 132 & 126 & 19.57 & 6 & 2.35 & 8.32 & 0.000 \\
\hline Magnetospirillum magnetotacticum & 116 & 40 & 43.48 & 76 & 24.12 & 1.80 & 0.033 \\
\hline Dethiobacter alkaliphilus & 101 & 97 & 10.87 & 4 & 1.76 & 6.16 & 0.017 \\
\hline Brevibacterium massiliense & 99 & 86 & 15.22 & 13 & 1.18 & 12.93 & 0.000 \\
\hline Eremococcus coleocola & 90 & 82 & 10.87 & 8 & 1.76 & 6.16 & 0.017 \\
\hline Anaeromusa acidaminophila & 86 & 85 & 15.22 & 1 & 0.59 & 25.87 & 0.000 \\
\hline Arthrobacter globiformis & 66 & 48 & 10.87 & 18 & 1.76 & 6.16 & 0.017 \\
\hline Staphylococcus epidermidis & 54 & 47 & 13.04 & 7 & 2.35 & 5.54 & 0.009 \\
\hline
\end{tabular}


Table 3 Bacteria prevalence in the vaginal microbiomes of women who delivered preterm and at term (Continued)

\begin{tabular}{|c|c|c|c|c|c|c|c|}
\hline \multirow[t]{2}{*}{ Species } & \multirow{2}{*}{$\begin{array}{l}\text { Total } \\
\text { reads }\end{array}$} & \multicolumn{2}{|c|}{ Preterm $(n=46)$} & \multicolumn{2}{|c|}{ Term $(n=170)$} & \multirow{2}{*}{$\begin{array}{l}\text { Prevalence } \\
\text { ratio }\end{array}$} & \multirow[t]{2}{*}{$\mathrm{FDR}^{*}$} \\
\hline & & Reads & Prevalence (\%) & Reads & Prevalence (\%) & & \\
\hline Corynebacterium simulans & 52 & 41 & 26.09 & 11 & 1.76 & 14.78 & 0.000 \\
\hline Anaeroglobus geminatus & 52 & 49 & 15.22 & 3 & 1.18 & 12.93 & 0.000 \\
\hline Cellvibrio gilvus & 42 & 26 & 15.22 & 16 & 1.76 & 8.62 & 0.000 \\
\hline Prosthecochloris vibrioformis & 41 & 40 & 6.52 & 1 & 0.59 & 11.09 & 0.028 \\
\hline Prevotella buccalis & 33 & 33 & 15.22 & 0 & 0.00 & - & 0.000 \\
\hline Acidaminococcus fermentans & 31 & 29 & 13.04 & 2 & 1.18 & 11.09 & 0.000 \\
\hline Brevibacterium casei & 25 & 24 & 8.70 & 1 & 0.59 & 14.78 & 0.005 \\
\hline Streptococcus sanguinis & 23 & 18 & 13.04 & 5 & 2.35 & 5.54 & 0.009 \\
\hline Atopobium parvulum & 23 & 20 & 8.70 & 3 & 1.18 & 7.39 & 0.023 \\
\hline Peptoniphilus duerdenii & 22 & 20 & 10.87 & 2 & 0.59 & 18.48 & 0.000 \\
\hline Pelobacter propionicus & 21 & 18 & 6.52 & 3 & 0.59 & 11.09 & 0.028 \\
\hline Staphylococcus hominis & 21 & 17 & 15.22 & 4 & 1.76 & 8.62 & 0.000 \\
\hline Atopostipes suicloacalis & 18 & 8 & 10.87 & 10 & 1.18 & 9.24 & 0.005 \\
\hline Corynebacterium pyruviciproducens & 18 & 13 & 13.04 & 5 & 1.76 & 7.39 & 0.005 \\
\hline Corynebacterium jeikeium & 14 & 11 & 13.04 & 3 & 0.59 & 22.17 & 0.000 \\
\hline Sporichthya polymorpha & 13 & 11 & 8.70 & 2 & 1.18 & 7.39 & 0.023 \\
\hline Rhodococcus jostii & 13 & 7 & 8.70 & 6 & 1.18 & 7.39 & 0.023 \\
\hline Nitrospina gracilis & 10 & 5 & 8.70 & 5 & 0.59 & 14.78 & 0.005 \\
\hline Megasphaera sp. BV3C16-1 & 10 & 9 & 6.52 & 1 & 0.59 & 11.09 & 0.028 \\
\hline
\end{tabular}

Panel A: species with greater prevalence in the term group (ratio term/preterm)

Panel B: species with greater prevalence in the preterm group (ratio preterm/term)

${ }^{*} F D R$ (false discovery rate) represents the corrected $p$ value for multiple comparisons

identified. The ALDEx2 analysis indicated that eight rare taxa were more abundant in the term group, which does not necessarily mean they are associated with a 'healthier' state or implicated in preventing SPTB. Since these bacteria are detected at very low abundance within the microbiota profiles, their biological significance in the vaginal microbiome is questionable. Differences in the prevalence of several other taxa between groups were also observed. For example, more women in the term group had Prevotella amnii and P. tannerae detected in their vaginal samples, whereas $P$. timonensis, $P$. bivia, $P$. corporis and $P$. bucalis were more frequently detected in samples from women in the preterm group (Table 3). Prevotella spp. have been previously associated with bacterial vaginosis and preterm labour [22, 66, 67], and our results indicate that different Prevotella species might have different roles in sPTB. Several of the taxa that were significantly different in their prevalence among women in the two groups also had low sequence read counts (Table 3). Further investigation would be required to determine if these rare members of the microbial community play a yet unknown role in SPTB.

It is also important to note that the number of bacterial species with greater prevalence in the preterm $(49 / 60)$ was higher than in the term $(11 / 60)$ cohort (Table 3$)$, which is consistent with our results of increased microbial richness and diversity in the samples from women who experienced preterm birth. This might indicate that increased richness, rather than the presence of specific taxa, might be associated with sPTB. Those differences might also be an indicator of physiological/biochemical dissimilarities in the vaginal microbiomes of women who deliver at term or preterm. In other words, the physiological state that leads to $\mathrm{SPTB}$ might also create an environment that supports a richer/more diverse microbiota.

Our results also confirmed previous reports of an association between Mycoplasma and preterm birth [68]. Mollicutes were detected significantly more often in women in the preterm group compared to women in the term group, but no differences were observed in Ureaplasma prevalence between groups indicating that the difference in Mollicutes prevalence is primarily driven by the presence of Mycoplasma spp. Although individual Mycoplasma species could not be discerned based on assay used in our study, both Mycoplasma genitalium [69-71] and Mycoplasma hominis [72-75] have been previously associated with negative reproductive outcomes including PTB.

Collectively, our overall findings were similar to other two studies, which provided us the opportunity to 
compare different study designs (based on different cohorts and barcode gene) that addressed the same research question. Hyman and colleagues [30] described the vaginal microbiota of 83 pregnant women (term $n=$ 66 , preterm $n=17$ ) based on Sanger sequencing of cloned 16S rRNA genes. Samples were collected at each trimester and preterm was defined as delivery before 37 weeks of gestation. There was no correlation between preterm and absence/low abundance of Lactobacillus in the microbiota; in other words, preterm outcome could not be predicted based on CST. Similar to our results, they found an association between increased microbiota diversity and preterm delivery among women of white ethnicity $(n=40)$ (data from women of others ethnicities was not included in the analysis because of small sample sizes). Although there was no association between CST and ethnicity, it is important to note that most women enrolled in this study described themselves as being white, and it is possible that an increased sample size of participants of other ethnicities could result in a different conclusion.

Romero and colleagues [29] also investigated the vaginal microbiota of pregnant women who experienced preterm, defined as delivery before 34 weeks of gestation (term $n=72$, preterm $n=18$ ). The profiles were created by $16 \mathrm{~S}$ rRNA amplicon sequencing, and samples were collected every 4 weeks until 24 weeks of gestation and then every 2 weeks. They found no differences in the frequency of different CST between women who had term and preterm deliveries. Likewise, no differences in bacteria relative abundance were observed between the two cohorts, although only bacteria that were present in at least $25 \%$ of samples were included in the analysis. These results are consistent with our findings of bacterial abundance based on the ALDEx analysis since we only found significant differences in relative abundance for eight rare bacteria. Unlike Hyman et al. [30] and our results, Romero et al. [29] did not find differences in microbiota diversity between women who delivered preterm and at term. One possible explanation for this contradictory result might be related to differences in participant ethnicity among these studies. While most women in our study and the Hyman et al. study described themselves as white, the majority of participants in the Romero et al. study described themselves as African American. It has been reported that the composition of the vaginal microbiota is strongly associated with a woman's ethnicity $[52,76]$. Other studies have also demonstrated that black ethnicity is associated with an increased microbiota diversity in comparison with white ethnicity [77], which could have masked differences in bacterial diversity between term and preterm cohorts in the Romero study.

Contrary to our overall findings, DiGiulio and colleagues [31] found a strong association between the
non-Lactobacillus-dominated CST IV and preterm birth in a case-control study based on the $16 \mathrm{~S}$ rRNA amplicon sequencing. Pregnant women (preterm $n=34$, term $n=15$ ), mostly of white ethnicity, were sampled weekly throughout gestation. Interestingly, the authors pointed out that if samples had been collected less frequently, short-term 'excursions' to CST IV would have been missed and probably the association between CST IV and preterm birth would have been less obvious. The detection of a temporary microbiota disturbance represented by a change from a Lactobacillus-dominated CST to CST IV may have been missed in our study since samples were not collected longitudinally. Moreover, a recent study has demonstrated that PTB-microbiota associations are population-dependent [32]; lower Lactobacillus and higher Gardnerella abundances were associated with PTB in a low-risk predominantly Caucasian cohort, but not in a high-risk predominantly African American cohort. These population-dependent associations might contribute to explain contradictory conclusions among different studies and emphasize the importance of investigating the vaginal microbiota of different populations with varying ethnic backgrounds and from different geographical locations.

Most samples in the preterm group were dominated by Lactobacillus, yet, they collectively had higher richness and diversity compared to samples from the term group. The increased microbiota richness/diversity might indicate a transient state between Lactobacillus-dominated CST and non-Lactobacillus-dominated, i.e., CST IV (A, C or D). In other words, the increased richness and diversity we observed might be a remnant characteristic of the previous disturbed microbiota. In summary, although we did not "detect" a specific microbial community structure that is associated with preterm birth, the increased microbiota richness/diversity was associated with preterm birth. In addition, the association with differences in Prevotella species and Mycoplasma presence may point to signature species associated with preterm birth.

\section{Conclusions}

Taken together, our results suggest that the differences in the microbiota of women who had preterm deliveries, such as increased microbiota richness and diversity and greater prevalence of Mollicutes and other bacteria, may have a role in SPTB. Other differences between cohorts might have been masked by the presence of highly dominant bacteria like Lactobacillus. At the overall level, we did not identify a specific vaginal microbial community structure at 11-16 weeks gestation age that predicts sPTB. Also, differences in relative abundance of bacterial species between term and preterm groups were only significant for a few low abundance species. Although a causal relationship remains to be determined, our results 
confirm previous reports of an association between Mollicutes and preterm birth, and further suggest that a diverse bacterial community may contribute to the microbiome's role in sPTB. Alternatively, the more rich and diverse microbiotas of the preterm group may reflect physiological differences between the groups that affect selection of bacteria. This study provides valuable evidence of subtle alterations in the microbiome associated with preterm birth that requires further study utilizing sequencing methodology. In addition, future study should include evaluation of the microbial metabolite production and host response to further elucidate factors leading to SPTB and identify women at risk early in pregnancy.

\section{Additional files}

Additional file 1: cpn60 OTU sequences. Multiple fasta file containing 728 OTU sequences. (TXT $336 \mathrm{~kb}$ )

Additional file 2: Summary of OTU analysed in this study. OTU ID, percentage of identity, length, cpnDB name, species, and abundance in each library are shown. (XLSX $500 \mathrm{~kb}$ )

\section{Acknowledgements}

The authors are grateful to the women who participated in the study and acknowledge the contribution and support of Ontario Birth Study Team members and the participants. The VOGUE Research Group is Deborah Money, Alan Bocking, Sean Hemmingsen, Janet Hill, Gregor Reid, Tim Dumonceaux, Gregory Gloor, Matthew Links, Kieran O'Doherty, Patrick Tang, Julianne van Schalkwyk and Mark Yudin.

\section{Funding}

Financial support was provided by a joint Canadian Institutes of Health Research (ClHR) Emerging Team Grant and a Genome British Columbia (GBC) grant awarded to DMM, AB and JEH (grant reference \#108030) as well as a CIHR grant MOP-82799 to AB. ACF was supported by a University of Saskatchewan graduate scholarship. Funding for the Ontario Birth Study was provided by Mount Sinai Hospital Foundation, Lunenfeld-Tanenbaum Research Institute and the Department of Obstetrics and Gynecology at Mount Sinai Hospital.

\section{Availability of data and materials}

The dataset supporting the results of this article is available in the NCBI SRA repository (Accession SRP073152, BioProject PRJNA317763; BioProject PRJNA403856)

\section{Authors' contributions}

$\mathrm{DM}, \mathrm{AB}$, JEH and the other members of the VOGUE Research Group conceived the study. DM, AB and JEH oversaw and contributed to data collection and participated in writing and manuscript review. ACF generated the Mollicutes PCR, 165 rRNA qPCR and the cpn60 microbiome profiles data, performed data analysis and wrote the paper. All authors read and approved the final manuscript.

\section{Ethics approval and consent to participate}

This study received ethical approval from the University of British Columbia Children's and Women's Research Ethics Board (Approval Number H14-01954), and Mount Sinai Hospital Research Ethics Board (Approval Number 15-0184-E). All participants provided written consent at enrolment.

\section{Consent for publication}

Not applicable.

\section{Competing interests}

The authors declare that they have no competing interests.

\section{Publisher's Note}

Springer Nature remains neutral with regard to jurisdictional claims in published maps and institutional affiliations.

\section{Author details}

'Department of Veterinary Microbiology, University of Saskatchewan, Saskatoon, SK S7N 5B4, Canada. ${ }^{2}$ Departments of Obstetrics and Gynaecology and Physiology, University of Toronto, Toronto, ON M5G 1L4, Canada. ${ }^{3}$ Lunenfeld-Tanenbaum Research Institute, M5T1X5, Toronto, ON, Canada. ${ }^{4}$ Department of Obstetrics and Gynaecology, University of British Columbia, Vancouver, BC V6T 1Z4, Canada. ${ }^{5}$ Women's Health Research Institute, BC Women's Hospital \& Health Centre, Vancouver, BC V6H 3N1, Canada.

Received: 19 October 2017 Accepted: 18 May 2018

Published online: 28 June 2018

\section{References}

1. WHO, March of Dimes, PMNCH, Save the Children. In: Howson CP, Kinney MV, Lawn JE, editors. Born too soon: the global action report on preterm birth. Geneva: World Health Organization; 2012.

2. Quinn J, Munoz FM, Gonik B, Frau L, Cutland C, Mallett-Moore T, et al. Preterm birth: case definition \& guidelines for data collection, analysis, and presentation of immunisation safety data. Vaccine. 2016;34:6047-56.

3. Blencowe H, Cousens S, Oestergaard MZ, Chou D, Moller AB, Narwal R, et al. National, regional, and worldwide estimates of preterm birth rates in the year 2010 with time trends since 1990 for selected countries: a systematic analysis and implications. Lancet. Elsevier Ltd. 2012;379:2162-72.

4. Behrman RE, Butler AS. In: Behrman RE, Butler AS, editors. Preterm birth: causes, consequences, and prevention. Washington, D.C.: National Academies Press; 2007.

5. Fraser AM, Brockert JE, Ward RH. Association of young maternal age with adverse reproductive outcomes. N Engl J Med. 1995;332:1113-8.

6. Jacobsson B, Ladfors L, Milsom I. Advanced maternal age and adverse perinatal outcome. Obstet Gynecol. 2004;104:727-33.

7. Schempf AH, Branum AM, Lukacs SL, Schoendorf KC. Maternal age and parity-associated risks of preterm birth: differences by race/ethnicity. Paediatr Perinat Epidemiol. 2007;21:34-43.

8. Han Z, Mulla S, Beyene J, Liao G, McDonald SD. Maternal underweight and the risk of preterm birth and low birth weight: a systematic review and meta-analyses. Int J Epidemiol. 2011;40:65-101.

9. Kistka ZAF, Palomar L, Lee KA, Boslaugh SE, Wangler MF, Cole FS, et al. Racial disparity in the frequency of recurrence of preterm birth. Am J Obstet Gynecol. 2007;196:1-6.

10. Conde-Agudelo A, Rosas-Bermúdez A, Kafury-Goeta AC. Birth spacing and risk of adverse perinatal outcomes. JAMA. 2006;295:1809-23.

11. Stock $\mathrm{S}$, Norman J. Preterm and term labour in multiple pregnancies. Semin Fetal Neonatal Med Elsevier Ltd. 2010:15:336-41.

12. Gardella C, Riley DE, Hitti J, Agnew K, Krieger JN, Eschenbach DA. Identification and sequencing of bacterial rDNAs in culture-negative amniotic fluid from women in premature labor. Am J Perinatol. 2004;21: 319-23.

13. Krohn MA, Hillier SL, Nugent RP, Cotch MF, Carey JC, Gibbs RS, et al. The genital flora of women with intraamniotic infection. J Infect Dis. 1995;171: $1475-80$.

14. Hillier SL, Martius J, Krohn M, Kiviat N, Holmes KK, Eschenbach DA. A casecontrol study of chorioamnionic infection and histologic chorioamnionitis in prematurity. N Engl J Med. 1988;319:972-8.

15. Romero R, Sirtori M, Oyarzun E, Avila C, Mazor M, Callahan R, et al. Infection and labor V. Prevalence, microbiology, and clinical significance of intraamniotic infection in women with preterm labor and intact membranes. Am J Obstet Gynecol. 1989;161:817-24.

16. Watts HD, Krohn MA, Hillier SL, Eschenbach DA. The association of occult amniotic fluid infection with gestational age and neonatal outcome among women in preterm labor. Obstet Gynecol. 1992;79:351-7.

17. Yoon BH, Romero R, Bin MJ, Shim S-S, Kim M, Kim G, et al. Clinical significance of intra-amniotic inflammation in patients with preterm labor and intact membranes. Am J Obstet Gynecol. 2001:185:1130-6.

18. DiGiulio DB, Romero R, Amogan HP, Kusanovic JP, Bik EM, Gotsch F, et al. Microbial prevalence, diversity and abundance in amniotic fluid during preterm labor: a molecular and culture-based investigation. PLoS One. 2008;3:e3056. 
19. Hillier SL, Witkin SS, Krohn MA, Watts DH, Kiviat NB, Eschenbach DA. The relationship of amniotic fluid cytokines and preterm delivery, amniotic fluid infection, histologic chorioamnionitis, and chorioamnion infection. Obstet Gynecol. 1993:81:941-8.

20. Jacobsson B, Mattsby-Baltzer I, Hagberg H. Interleukin-6 and interleukin-8 in cervical and amniotic fluid: relationship to microbial invasion of the chorioamniotic membranes. BJOG An Int. J. Obstet. Gynaecol. 2005;112:719-24.

21. Nugent RP, Krohn MA, Hillier SL. Reability of diagnosing bacterial vaginosis is improved by standardized method of gram stain interpretation. J Clin Microbiol. 1991;29:297-301.

22. Hill GB. The microbiology of bacterial vaginosis. Am J Obstet Gynecol. 1993; 169:450-4.

23. Romero R, Hassan SS, Gajer P, Tarca AL, Fadrosh DW, Nikita L, et al. The composition and stability of the vaginal microbiota of normal pregnant women is different from that of non-pregnant women. Microbiome. 2014;2:1-19.

24. Freitas AC, Chaban B, Bocking A, Rocco M, Yang S, Hill JE, et al. The vaginal microbiome of pregnant women is less rich and diverse, with lower prevalence of Mollicutes, compared to non-pregnant women. Sci Rep. 2017;7:1-16.

25. Aagaard KM, Riehle K, Ma J, Segata N, Mistretta TA, Coarfa C, et al. A metagenomic approach to characterization of the vaginal microbiome signature in pregnancy. PLoS One. 2012;7:e36466.

26. Walther-António MRS, Jeraldo P, Berg Miller ME, Yeoman CJ, Nelson KE, Wilson BA, et al. Pregnancy's stronghold on the vaginal microbiome. PLoS One. 2014;9:e98514.

27. Maclntyre DA, Chandiramani M, Lee YS, Kindinger L, Smith A, Angelopoulos $\mathrm{N}$, et al. The vaginal microbiome during pregnancy and the postpartum period in a European population. Sci Rep. 2015;5:1-9.

28. Leitich H, Bodner-Adler B, Brunbauer M, Kaider A, Egarter C, Husslein P. Bacterial vaginosis as a risk factor for preterm delivery: a meta-analysis. Am J Obstet Gynecol. 2003;189:139-47.

29. Romero R, Hassan SS, Gajer P, Tarca AL, Fadrosh DW, Bieda J, et al. The vaginal microbiota of pregnant women who subsequently have spontaneous preterm labor and delivery and those with a normal delivery at term. Microbiome. 2014;2:1-15.

30. Hyman RW, Fukushima M, Jiang H, Fung E, Rand L, Johnson B, et al. Diversity of the vaginal microbiome correlates with preterm birth. Reprod Sci. 2014;21:32-40.

31. DiGiulio DB, Callahan BJ, Mcmurdie PJ, Costello EK, Lyell DJ, Robaczewska A, et al. Temporal and spatial variation of the human microbiota during pregnancy. Proc Natl Acad Sci U S A. 2015;112:11060-5.

32. Callahan BJ, DiGiulio DB, Goltsman DSA, Sun CL, Costello EK, Jeganathan P, et al. Replication and refinement of a vaginal microbial signature of preterm birth in two racially distinct cohorts of US women. Proc Natl Acad Sci U S A. 2017;114:9966-71.

33. Links MG, Dumonceaux TJ, Hemmingsen SM, Hill JE. The chaperonin-60 universal target is a barcode for bacteria that enables de novo assembly of metagenomic sequence data. PLoS One. 2012;7:e49755.

34. Paramel Jayaprakash T, Schellenberg JJ, Hill JE. Resolution and characterization of distinct cpn60-based subgroups of Gardnerella vaginalis in the vaginal microbiota. PLoS One. 2012;7:e43009.

35. Harris PA, Taylor R, Thielke R, Payne J, Gonzalez N, Conde JG. Research electronic data capture (REDCap) — a metadata-driven methodology and workflow process for providing translational research informatics support. J Biomed Inform Elsevier Inc. 2009;42:377-81.

36. Lee DH, Zo YG, Kim SJ. Nonradioactive method to study genetic profiles of natural bacterial communities by PCR - single-strand-conformation polymorphism. Appl Environ Microbiol. 1996;62:3112-20.

37. Chaban B, Albert AYK, Links MG, Gardy J, Tang P, Hill JE. Characterization of the upper respiratory tract microbiomes of patients with pandemic $\mathrm{H} 1 \mathrm{~N} 1$ influenza. PLoS One. 2013;8:e69559.

38. Hill JE, Penny SL, Crowell KG, Goh SH, Hemmingsen SM. cpnDB: a chaperonin sequence database. Genome Res. 2004;14:1669-75.

39. van Kuppeveld FJM, van der Logt JTM, Angulo AF, van Zoest MJ, Quint WGV, Niesters HGM, et al. Genus- and species-specific identification of mycoplasmas by $16 \mathrm{~S}$ rRNA amplification. Appl Environ Microbiol. 1992;58:2606-15.

40. Watson HL, Blalock DK, Cassell GH. Variable antigens of Ureaplasma urealyticum containing both serovar-specific and serovar-cross-reactive epitopes. Infect Immun. 1990;58:3679-88.

41. Chaban B, Links MG, Jayaprakash TP, Wagner EC, Bourque DK, Lohn Z, et al. Characterization of the vaginal microbiota of healthy Canadian women through the menstrual cycle. Microbiome. 2014;2:1-12.
42. Hill JE, Town JR, Hemmingsen SM. Improved template representation in cpn60 polymerase chain reaction (PCR) product libraries generated from complex templates by application of a specific mixture of PCR primers. Environ Microbiol. 2006;8:741-6.

43. Schellenberg JJ, Links MG, Hill JE, Dumonceaux TJ, Kimani J, Jaoko W, et al. Molecular definition of vaginal microbiota in East African commercial sex workers. Appl Environ Microbiol. 2011;77:4066-74.

44. Links MG, Chaban B, Hemmingsen SM, Muirhead K, Hill JE. mPUMA: a computational approach to microbiota analysis by de novo assembly of operational taxonomic units based on protein-coding barcode sequences. Microbiome. 2013;1:1-7.

45. Grabherr MG, Haas BJ, Yassour M, Levin JZ, Thompson DA, Amit I, et al. Fulllength transcriptome assembly from RNA-Seq data without a reference genome. Nat Biotechnol. 2011;29:644-52.

46. Schellenberg JJ, Links MG, Hill JE, Dumonceaux TJ, Peters GA, Tyler SD, et al. Pyrosequencing of the chaperonin-60 universal target as a tool for determining microbial community composition. Appl Environ Microbiol. 2009;75:2889-98.

47. Benjamini $Y$, Hochberg $Y$. Controlling the false discovery rate: a practical and powerful approach to multiple testing. J R Stat Soc. 1995;57:289-300.

48. Caporaso JG, Kuczynski J, Stombaugh Jl, Bittinger K, Bushman FD, Costello EK, et al. QIIME allows analysis of high-throughput community sequencing data. Nat Methods. 2010;7:335-6.

49. Oksanen AJ, Blanchet FG, Kindt R, Legendre P, Minchin PR, Hara RBO, et al. Community Ecology Package "vegan". R version 2.3-1. Available: https://cran. r-project.org/web/packages/vegan/. 2015.

50. Endres DM, Schindelin JE. A new metric for probability distributions. IEEE Trans Inf Theory. 2003;49:1858-60.

51. Fernandes AD, Macklaim JM, Linn TG, Reid G, Gloor GB. ANOVA-like differential expression (ALDEX) analysis for mixed population RNA-Seq. PLOS One. 2013;8:e67019.

52. Ravel J, Gajer P, Abdo Z, Schneider GM, Koenig SSK, McCulle SL, et al. Vaginal microbiome of reproductive-age women. Proc Natl Acad Sci U S A. 2011;108:4680-7.

53. Albert AYK, Chaban B, Wagner EC, Schellenberg JJ, Links MG, van Schalkwyk J, et al. A study of the vaginal microbiome in healthy Canadian women utilizing cpn60-based molecular profiling reveals distinct Gardnerella subgroup community state types. PLoS One. 2015;10:e0135620.

54. Nasioudis D, Forney LJ, Schneider GM, Gliniewicz K, France M, Boester A, et al. Influence of pregnancy history on the vaginal microbiome of pregnant women in their first trimester. Sci. Rep. Springer US; 2017;7:1-6.

55. Mercer BM, Goldenberg RL, Moawad AH, Meis PJ, lams JD, Das AF, et al. The preterm prediction study: effect of gestational age and cause of preterm birth on subsequent obstetric outcome. Am J Obstet Gynecol. 1999;181:1216-21.

56. Goldenberg RL, Hauth JC, Andrews WW. Intrauterine infection and preterm delivery. N Engl J Med. 2000;342:1500-7.

57. Kindinger LM, Bennett PR, Lee YS, Marchesi JR, Smith A, Cacciatore S, et al. The interaction between vaginal microbiota, cervical length, and vaginal progesterone treatment for preterm birth risk. Microbiome. 2017:5:1-14.

58. Kekki M, Kurki T, Pelkonen J, Kukinen-Raty M, Cacciatore B, Paavonen J. Vaginal clindamycin in preventing preterm birth and peripartal infections in asymptomatic women with bacterial vaginosis: a randomized, controlled trial. Obstet Gynecol. 2001;97:643-8.

59. Andrews WW, Goldenberg RL, Hauth JC, Cliver SP, Copper R, Conner M. Interconceptional antibiotics to prevent spontaneous preterm birth: a randomized clinical trial. Am J Obstet Gynecol. 2006;194:617-23.

60. Morency A, Bujold E. The effect of second-trimester antibiotic therapy on the rate of preterm birth. J Obstet Gynaecol Canada. 2007;29:35-44.

61. Okun N, Gronau KA, Hannah ME. Antibiotics for bacterial vaginosis or Trichomonas vaginalis in pregnancy: a systematic review. Obstet Gynecol. 2005;105:857-68.

62. Thinkhamrop J, Hofmeyr GJ, Adetoro O, Lumbiganon P, Ota E. Antibiotic prophylaxis during the second and third trimester to reduce adverse pregnancy outcomes and morbidity. Cochrane Database Syst Rev. 2015;1: CD002250,

63. Beigi RH, Austin MN, Meyn LA, Krohn MA, Hillier SL. Antimicrobial resistance associated with the treatment of bacterial vaginosis. Am J Obstet Gynecol. 2004:191:1124-9.

64. Budd W, Bostwick DG, Woody J, Hunt C. Antimicrobial resistance genes and modelling of treatment failure in bacterial vaginosis: clinical study of 289 symptomatic women. J Med Microbiol. 2016;65:377-86. 
65. Brown RG, Marchesi JR, Lee YS, Smith A, Lehne B, Kindinger LM, Terzidou V, Holmes E, Nicholson JK, Bennett PR, et al. Vaginal dysbiosis increases risk of preterm fetal membrane rupture, neonatal sepsis and is exacerbated by erythromycin. BMC Med. 2018;16(1):9.

66. Paramel Jayaprakash T, Wagner EC, van Schalkwyk J, Albert AYK, Hill JE, Money DM. High diversity and variability in the vaginal microbiome in women following preterm premature rupture of membranes (PPROM): a prospective cohort study. PLoS One. 2016;11:e0166794.

67. Ling Z, Kong J, Liu F, Zhu H, Chen X, Wang Y, et al. Molecular analysis of the diversity of vaginal microbiota associated with bacterial vaginosis. BMC Genomics. 2010;11:1-16.

68. Foxman B, Wen A, Srinivasan U, Goldberg D, Marrs CF, Owen J, et al. Mycoplasma, bacterial vaginosis-associated bacteria BVAB3, race, and risk of preterm birth in a high-risk cohort. Am J Obstet Gynecol. 2014;210:226.e1-7.

69. Hitti J, Garcia P. Totten P, Paul K, Astete S, Holmes KK. Correlates of cervical Mycoplasma genitalium and risk of preterm birth among Peruvian women. Sex Transm Dis. 2010;37:81-5.

70. Edwards RK, Ferguson RJ, Reyes L, Brown M, Theriaque DW, Duff P. Assessing the relationship between preterm delivery and various microorganisms recovered from the lower genital tract. J. Matern. Neonatal Med. 2006;19:357-63.

71. Lis R, Rowhani-Rahbar A, Manhart LE. Mycoplasma genitalium infection and female reproductive tract disease: a meta-analysis. Clin Infect Dis. 2015;61: 418-26.

72. Donders GG, Van Calsteren K, Bellen G, Reybrouck R, Van Den Bosch T, Riphagen I, et al. Predictive value for preterm birth of abnormal vaginal flora, bacterial vaginosis and aerobic vaginitis during the first trimester of pregnancy. BJOG An Int J Obstet Gynaecol. 2009;116:1315-24.

73. Kwak D-W, Hwang H-S, Kwon J-Y, Park Y-W, Kim Y-H. Co-infection with vaginal Ureaplasma urealyticum and Mycoplasma hominis increases adverse pregnancy outcomes in patients with preterm labor or preterm premature rupture of membranes. J Matern Neonatal Med. 2014;27:333-7.

74. Hillier SL, Nugent RP, Eschenbach DA, Krohn MA, Gibbs RS, Martin DH, et al. Association between bacterial vaginosis and preterm delivery of a low-birthweight infant. N Engl J Med. 1995;333:1737-42.

75. Lamont RF, Taylor-Robinson D, Wigglesworth JS, Furr PM, Evans RT, Elder MG. The role of mycoplasmas, ureaplasmas and chlamydiae in the genital tract of women presenting in spontaneous early preterm labour. J Med Microbiol. 1987:24:253-7.

76. Zhou X, Brown CJ, Abdo Z, Davis CC, Hansmann MA, Joyce P, et al. Differences in the composition of vaginal microbial communities found in healthy Caucasian and black women. ISME J. 2007;112:121-33.

77. Fettweis JM, Brooks JP, Serrano MG, Sheth NU, Girerd PH, Edwards DJ, et al. Differences in vaginal microbiome in African American women versus women of European ancestry. Microbiology. 2014;160:2272-82.

\section{Ready to submit your research? Choose BMC and benefit from:}

- fast, convenient online submission

- thorough peer review by experienced researchers in your field

- rapid publication on acceptance

- support for research data, including large and complex data types

- gold Open Access which fosters wider collaboration and increased citations

- maximum visibility for your research: over $100 \mathrm{M}$ website views per year

At BMC, research is always in progress.

Learn more biomedcentral.com/submissions 